\title{
A facile three-step synthetic pathway to fused bicyclic hydantoins using selenocyclization step
}

\author{
Biljana M. Šmit ${ }^{*}$ and Radoslav Z. Pavlović \\ Faculty of Science, University of Kragujevac, Radoja Domanovića 12 P.O. Box 60, 34000 Kragujevac, Serbia, \\ biljam@kg.ac.rs
}

\begin{abstract}
Sequential 5-alkenyl hydantoin and pyrrolidine ring-forming reactions have been applied in the synthesis of conformationally constrained fused bicyclic scaffold. They are assembled in only three-step reaction sequence from two variable building blocks by combining Bucherer-Bergs reaction with a final selenium-promoted intramolecular cyclization as a key step. The reaction is regiospecific giving only five-membered fused bicyclic hydantoins in good to excellent yields via favourable 5-exo-trig ring closure process.
\end{abstract}

Imidazolidine-2,4-dione derivatives, generally called hydantoins ${ }^{1}$, are important class of compounds because of their industrial relevance as intermediates in the production of $\alpha$-amino acids ${ }^{2}$ and their frequent use in a plethora of pharmaceutical products ${ }^{3}$.

Hydantoins represent ubiquitous structural core sporadically found in a number of natural products ${ }^{4}$. Several derivatives exhibit diverse biological activities, such as anticolvulsant ${ }^{5}$, antitumor ${ }^{6}$, anticancer ${ }^{7}$, antiarrythmic ${ }^{8}$, herbicidal $^{9}$, and others. The observed activities do not arise from hydantoin nucleus itself but from different substituents that have been appended to $\mathrm{it}^{10}$. Especially, spirohydantoins ${ }^{11}$ and fused ${ }^{12}$ bicyclic hydantoin derivatives have recently attracted much attention in drug discovery due to their various biological activities. However, the methods for their synthesis are not numerous. Only few examples have dealt with the construction of six and five membered fused hydantoins using ring-closing metathesis, where amino acids have been used as starting materials to prepare the hydantoin precursors ${ }^{13}$. Therefore, an extensive development of new synthetic methodologies for the preparation of new functionalized hydantoin derivatives would be highly desirable.

As part of our strategy towards the preparation of hydantoin-containing heterocycles, we sought to prepare the more conformationally constrained and varied bicyclic scaffolds, by fusing the hydantoin ring at N-1 and C-5 positions to a functionalized five-membered pyrrolidine ring and homologues. Furthermore, the presence of substituents in $\mathrm{C}-5$ and $\mathrm{N}-3$ position open up capability of generating a broad structural diversity.

Although selenocyclization proved to be a powerful and versatile tool for the construction of heterocyclic rings ${ }^{14}$, no examples of construction of the bicyclic hydantoin system through selenium-induced cyclization have been reported.

Herein, we describe the de novo design and synthesis of a bicyclic hydantoin scaffold and our independent efforts to exploit intramolecular selenocyclization for fashioning molecules having rigid, conformationally well-defined structures consistent with attractive lead compounds for drug discovery.

For our study, in the first step, unsaturated ketones 1a-g as starting materials were synthesized from readily available $\beta$-ketoesters (Scheme 1). For the preparation of 5-alkenyl hydantoins, we have chosen the use of the wellestablished Bucherer-Bergs reaction ${ }^{15}$ because this reaction, compatible with a large-scale production, uses non expensive reagents as well as mild conditions and proceed in one step starting from the appropriate unsaturated ketones. Under these conditions (i.e. 1 equiv of ketone 1a-g, 2 equiv of $\mathrm{NaCN}, 4$ equiv of $\left(\mathrm{NH}_{4}\right)_{2} \mathrm{CO}_{3}, \mathrm{EtOH}-\mathrm{H}_{2} \mathrm{O}$ (1:1), reflux, 24 h) compounds $\mathbf{2 a - g}$, as crystalline solids, were obtained in good yields (61-89\%). 
The resulting 5-alkenyl hydantoins contains a double bond and an internal nitrogen nucleophile, and they can be subjected to electrophilic cyclization. In the final step, 5-alkenyl hydantoins 2a-g were submitted separately to the selenium-induced cyclization reaction. The overall 3 step sequence to fused bicyclic hydantoins is shown in Scheme 1.

Scheme 1. Synthesis of fused bicyclic hydantoins

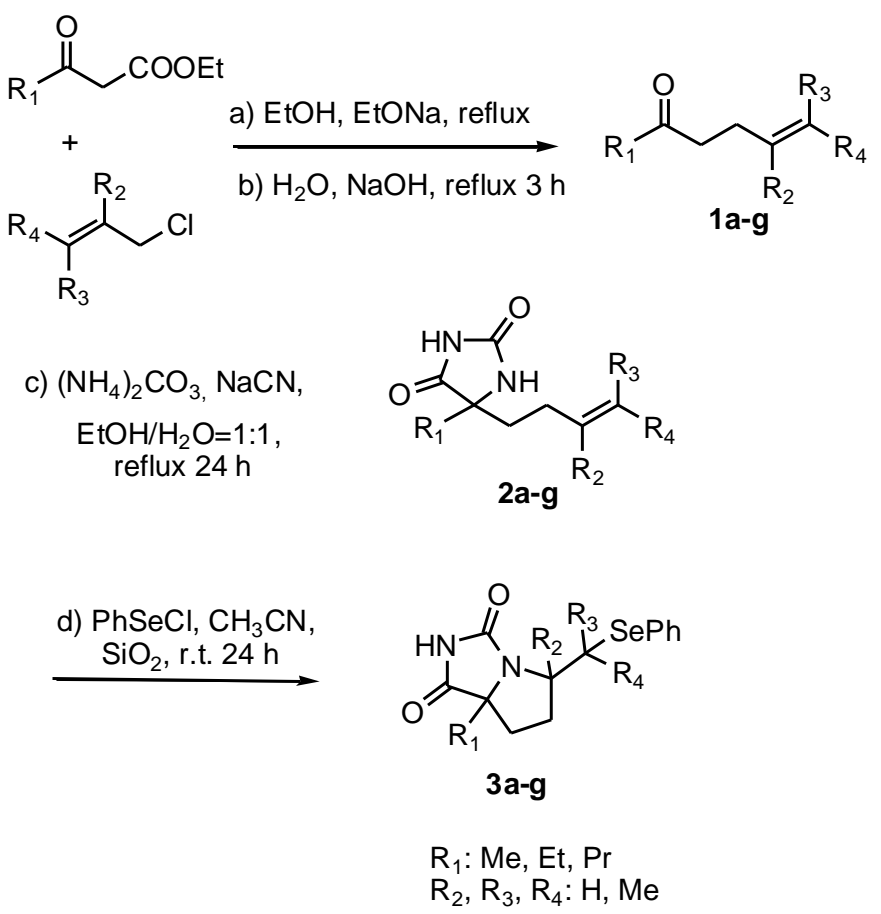

We initiated our study by optimization of the reaction conditions. The influence of selenium reagents, bases, additives, temperature and solvents on the cyclization of $\mathbf{2 g}$ was examined. Interestingly, chemoselectivity of bicyclic hydantoin formation is strongly influenced by experimental factors such as the solvent and the use of additives.

After an initial screen of additives (Table 1) we found that the use of $\mathrm{SiO}_{2}$ afforded the highest yield of desired product. Concerning the solvents, the use of acetonitrile gave the best results. The use of THF, dichloromethane or pyridine gave the desired product in the yield less than $10 \%$. In our previous works ${ }^{16}$ we found that the use of bases facilitates the selenoetherification, but in this cyclization reaction the use of bases $\left(\mathrm{K}_{2} \mathrm{CO}_{3}, \mathrm{Et}_{3} \mathrm{~N}\right.$ or pyridine) did not have any influence. The effect of reaction temperature is also shown in Table 1 and the highest yield was obtained at ambient temperature.

The effect of halide ion of the selenylating reagent on the reaction outcome has been observed. Although phenylselenyl bromide is most effective reagent for intramolecular amidoselenylations ${ }^{17}$, in our screening it is less successful than chloride and iodide (Table 1).

From the results above, optimum reaction conditions were chosen: alkenyl-hydantoin (1 equiv), $\mathrm{PhSeCl}(1.1$ equiv), silica gel (5 equiv), acetonitrile as solvent and room temperature. Using the optimized conditions, selenocyclization with a variety of 5-alkenyl hydantoins was next explored. In all cases clean formation of fused bicyclic hydantoins was observed. From the results summarized in Table 2, it is apparent that good to excellent yields of fused bicyclic hydantoins are obtained. 
The reaction is regiospecific giving only five-membered fused bicyclic hydantoins stemming from the nucleophilic attack of the nitrogen atom to cyclic selenuranium ion intermediate during the cyclization step. Formation of this sole regioisomer proceed via favorable 5-exo-trig ring closure process.

The reaction tolerates a variety of substitution on double bond. Precursors with allyl 2a-c and metallyl 2d-f substituents afforded bicyclic products in high yield. In the case of analogue with terminally disubstituted double bond $\mathbf{2 g}$ yield was lower probably due to steric hindrance. Size of alkyl substituents at C5 position in precursors decreased the yield of the products (3c and $\mathbf{3 f})$.

Also we tested the reactivity of N3-alkylated alkenyl hydantoins $\mathbf{2 h}$ and $\mathbf{2 i}$. The cyclization proceeded well which open up the possibility to prepare a great number of products with high diversity.

Finally we tried to obtain the bridged bicyclic hydantoin by cyclization via N3 nitrogen atom from N1-acetylated hydantoin, but this attempt failed.

Table 1. Optimization of the reaction conditions ${ }^{a}$ for the selenocyclization of alkenyl hydantoin $\mathbf{2 g}$

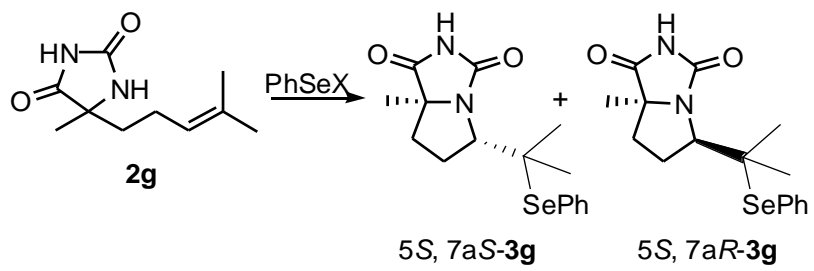

\begin{tabular}{cccccc}
\hline entry & $\mathrm{X}$ & temperature $\left({ }^{\circ} \mathrm{C}\right)$ & additive & ${\text { yield }(\%)^{d}}^{d}$ & $\mathrm{dr}^{d}$ \\
\hline 1 & $\mathrm{Cl}$ & 25 & $\mathrm{None}^{d}$ & 6 & - \\
2 & $\mathrm{Cl}$ & 25 & $\mathrm{Al}_{2} \mathrm{O}_{3}$ & 4 & - \\
3 & $\mathrm{Cl}$ & 25 & $\mathrm{AlCl}_{3}$ & 6 & - \\
4 & $\mathrm{Cl}$ & 25 & $\mathrm{ZnCl}_{2}$ & 5 & - \\
5 & $\mathrm{Cl}$ & 25 & $\mathrm{SnCl}_{2}$ & $26^{e}$ & $72: 27$ \\
6 & $\mathrm{Cl}$ & 25 & $\mathrm{BF}_{3} \cdot \mathrm{OEt}_{2}$ & $35^{e}$ & $84: 16$ \\
7 & $\mathrm{Cl}$ & 25 & $\mathrm{SiO}_{2}$ & $41^{e}$ & $84: 16$ \\
$8^{b}$ & $\mathrm{Cl}$ & 25 & $\mathrm{SiO}_{2}$ & $56^{e}$ & $81: 19$ \\
9 & $\mathrm{Cl}$ & 25 & $\mathrm{~K}_{2} \mathrm{CO}_{3}$ & 6 & - \\
10 & $\mathrm{Cl}$ & 25 & $\mathrm{Et}_{3} \mathrm{~N}$ & 11 & - \\
11 & $\mathrm{Cl}$ & 25 & $\mathrm{Py}$ & 9 & - \\
$12^{b}$ & $\mathrm{Cl}$ & -5 & $\mathrm{SiO}_{2}$ & $43^{e}$ & $80: 20$ \\
$13^{b}$ & $\mathrm{Cl}$ & 81 & $\mathrm{SiO}_{2}$ & 22 & - \\
$14^{b}$ & $\mathrm{Br}$ & 25 & $\mathrm{SiO}_{2}$ & 4 & - \\
$15^{b, c}$ & $\mathrm{I}$ & 25 & $\mathrm{SiO}_{2}$ & $68^{e}$ & $87: 13$
\end{tabular}

${ }^{a}$ Reaction conditions: 5-Methyl-5-(4-methyl-pent-3-enyl)-imidazolidine-2,4-dione (2g, 0.5 mmol), additive $(0.5 \mathrm{mmol})$, acetonitrile $5 \mathrm{~mL}, \mathrm{PhSeX}(0.55 \mathrm{mmol}) .{ }^{b}$ The reaction was conducted with $2.5 \mathrm{mmol}$ of $\mathrm{SiO}_{2} .{ }^{c} \mathrm{PhSeI}$ was prepared by the reaction of $(\mathrm{PhSe})_{2}$ with one equiv of iodine. ${ }^{d}$ Determined from ${ }^{1} \mathrm{H}$ NMR spectra of crude reaction mixture. ${ }^{e}$ Isolated yields.

These reactions proceeded in stereoselective manner obtaining the separable diastereomeric mixture. The products with bridgehead substituents and $\mathrm{CH}_{2} \mathrm{SePh}$ (or $\mathrm{CMe}_{2} \mathrm{SePh}$ ) groups in cis relationship were formed predominantly. The observed diastereomeric ratios and chemical yields are summarized in Table 2. 
Table 2. Selenocyclization ${ }^{a}$ of 5-alkenyl hydantoins

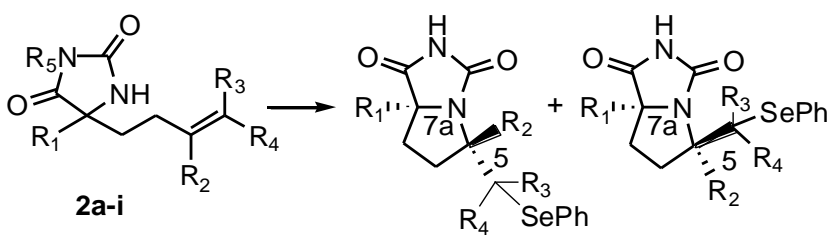

3a-i

\begin{tabular}{clccc}
\hline substrate & $\mathrm{R}_{1} / \mathrm{R}_{2} / \mathrm{R}_{3} / \mathrm{R}_{4} / \mathrm{R}_{5}$ & product & yield $(\%)^{b}$ & $\mathrm{dr}^{c}$ \\
\hline $\mathbf{2 a}$ & $\mathrm{Me} / \mathrm{H} / \mathrm{H} / \mathrm{H} / \mathrm{H}$ & $\mathbf{3 a}$ & 96 & $86: 14$ \\
$\mathbf{2 b}$ & $\mathrm{Et} / \mathrm{H} / \mathrm{H} / \mathrm{H} / \mathrm{H}$ & $\mathbf{3 b}$ & 92 & $84: 16$ \\
$\mathbf{2 c}$ & $\mathrm{Pr} / \mathrm{H} / \mathrm{H} / \mathrm{H} / \mathrm{H}$ & $\mathbf{3 c}$ & 72 & $62: 37$ \\
$\mathbf{2 d}$ & $\mathrm{Me} / \mathrm{Me} / \mathrm{H} / \mathrm{H} / \mathrm{H}$ & $\mathbf{3 d}$ & 89 & $64: 36$ \\
$\mathbf{2 e}$ & $\mathrm{Et} / \mathrm{Me} / \mathrm{H} / \mathrm{H} / \mathrm{H}$ & $\mathbf{3 e}$ & 98 & $54: 46$ \\
$\mathbf{2 f}$ & $\mathrm{Pr} / \mathrm{Me} / \mathrm{H} / \mathrm{H} / \mathrm{H}$ & $\mathbf{3 f}$ & 73 & $72: 28$ \\
$\mathbf{2 g}$ & $\mathrm{Me} / \mathrm{H} / \mathrm{Me} / \mathrm{Me} / \mathrm{H}$ & $\mathbf{3 g}$ & 56 & $81: 19$ \\
$\mathbf{2 h}$ & $\mathrm{Me} / \mathrm{H} / \mathrm{Me} / \mathrm{Me} / \mathrm{Me}$ & $\mathbf{3 h}$ & 66 & $83: 17$ \\
$\mathbf{2 i}$ & $\mathrm{Me} / \mathrm{H} / \mathrm{Me} / \mathrm{Me} / \mathrm{Bn}$ & $\mathbf{3 i}$ & 42 & $85: 15$
\end{tabular}

${ }^{a}$ The reactions were conducted using $2.5 \mathrm{mmol}$ of $\mathrm{SiO}_{2}, 0.55 \mathrm{mmol}$ of $\mathrm{PhSeCl}$ and 0.5 mmol of alkenyl hydantoin $(\mathbf{2 a - i})$ in acetonitrile $(5 \mathrm{~mL}) .{ }^{b}$ Isolated yield. ${ }^{c}$ Diastereoisomer ratios $(7 \mathrm{a} S, 5 S: 7 \mathrm{a} S, 5 R)$ were determined from ${ }^{1} \mathrm{H}$ NMR spectra of crude reaction mixture.

The exclusively cis fusion of the bicyclic system was established on the basis of the chemical shifts of the proton and carbon- 13 at the 7 a position ${ }^{18}$. In the major diastereoisomer the $(5 S, 7 \mathrm{a} S)$ configuration to the stereogenic centers was assigned.

Thus, we have an easy access to azabicyclic compound bearing nitrogen at the fusion of five-membered rings, which are key building blocks in many multistep alkaloids and drug syntheses. Due to the presence of the carbonyl and phenylselenium groups, these products can be employed for further interesting transformations ${ }^{17 a}$.

In summary, we have described a short and convenient method for the preparation of fused bicyclic hydantoins, in good to excellent yields, starting from simple commercially available materials in only three-step reaction sequence, including intramolecular electrophilic amidoselenylation of 5-alkenyl hydantoins as an assential step. The excellent chemo- and regioselectivity are an important advantage of this method. This methodology would be extended to access six membered ring systems.

Acknowledgment. This work was supported by the Ministry of Education, Science and Technological Development of the Republic of Serbia (Pr. No. 172011).

\section{References}

1. (a) Lopez, C. A.; Trigo, G. G. Adv. Heterocycl. Chem. 1985, 119, 7595. (b) Ware, E. Chem. Rev. 1950, 46, 403. (c) Meusel, M.; Gütschow, M. Org. Prep. Proced. Int. 2004, 36, 391.

2. Hoppe, B.; Martens, J. Chem. Unserer Zeit 1984, 18, 73.

3. (a) Claeys, D. D.; Stevens, C. V.; Dieltiens, N. Eur. J. Org. Chem. 2008, 171. (b) Muccioli, G. G.; Martin, D.; Scriba, G. K. E.; Poppitz, W.; Poupaert, J. H.; Wouters, J.; Lambert, D. M. J. Med. Chem. 2005, 48, 2509. (c) Zha, C.; Brown, G. B.; Brouillett, W. J. J. Med. Chem. 2004, 47, 6519. (d) Jansen, M.; Potschka, H.; Brandt, C.; Löscher, W.; Dannhardt, G. J. Med. Chem. 2003, 46, 64. (e) Kumar, V.; Kaushik, M. P.; Mazumdar, A. Eur. J. Org. Chem. 2008, 1910. (f) Zhang, D.; Xing, X.; Cuny, G. D. J. Org. Chem. 2006, 71, 1750. (g) Diafi, L.; Rubat, C.; Coudert, P.; Bastide, P.; Margoum, N.; Tronche, P. Eur. J. Med. Chem. 1991, 26, 231. (h) Karolacawojciechowska, J.; Kwiatkowski, W.; Kieckonono, K. Pharmazie 1995, 50, 114. (i) Vázquez, J.; Royo, M.; 
Albericio, F. Lett. Org. Chem. 2004, 1, 224. (j) Meusel, M.; Ambrozak, A.; Hecker, T. K.; Gütschow, M. J. Org. Chem. 2003, 68, 4684.

4. (a) Cachet, N.; Genta-Jouve, G.; Regalado, E. L.; Mokrini, R.; Amade, P.; Culioli, G.; Thomas, O. P. J. Nat. Prod. 2009, 72, 1612. (b) Jakse, R.; Kroselj, V.; Recnik, S.; Sorsak, G.; Svete, J.; Stanovnik, B.; Grdadolnik, S. G. Z. Naturforsch $2002,57 b, 453$. (c) Kazlauskas, R.; Murphy, P. T.; Quinn, R. J.; Wells, T. J. Tetrahedron Lett. 1977, 61.

5. (a) El-Kerdawy, M. M.; Tantawy, A. S.; Abououf, A. A. Egypt. J. Chem. 1974, 17, 845. (b) Dziedzic, B.; Szadowska, A.; Kaminska, A. Acta Pol. Pharm. 1978, 35, 423. (c) Scholl, S.; Koch, A.; Henning, D.; Kempter, D.; Kleinpeter, E. Struct. Chem. 1999, 10, 355 .

6. (a) Rodgers, T. R.; Lamontagne, M. P.; Markovac, A.; Ash, A. B. J. Med. Chem. 1977, 20, 591. (b) Struck, R. F.; Kirk, M. C.; Rice, L. S.; Suling, W. J. J. Med. Chem. 1986, 29, 1319.

7. Suzen, S.; Buyukbingol, E. Farmaco 2000, 55, 246.

8. (a) Knabe, J.; Baldauf, J.; Ahlhem, A. Pharmazie 1997, 52, 912. (b) Anger, T.; Madge, D. J.; Mulla, M.; Riddall, D. J. Med. Chem. 2001, 44, 115. (c) Matsukura, M.; Daiku, Y.; Ucda, K.; Tanaka, S.; Igarashi, T.; Minami, N. Chem. Pharm. Bull. 1992, 40, 1823.

9. (a) Haruyama, H.; Takayama, T.; Kinoshita, T.; Kondo, M.; Nakajima, M.; Haneishi, T. J. Chem. Soc. Perkin Trans. 1 1991, 1637. (b) Mio, S.; Ichinose, R.; Goto, K.; Sugaai, S.; Sato, S. Tetrahedron 1991, 47, 2111. (c) Mio, S.; Shiraishi, M.; Sugaai, S.; Haruyama, H.; Sato, S. Tetrahedron 1991, 47, 2121. (d) Mio, S.; Kumagawa, Y.; Sugaai, S. Tetrahedron Lett. $1993,34,7391$. 10. (a) Moloney, G.P.; Martin, G. R.; Mathews, N.; Milne, A.; Hobbs, H.; Dosworth, S.; Sang, P. Y.; Knight, C.; Williams, M.; Maxwell, M.; Glen, R. C. J. Med. Chem. 1999, 42, 2504. (b) Somsák, L.; Kovácz, L.; Tóth, M.; Ösz, E.; Szilágyi, L.; Györgydeák, Z.; Dinya, Z.; Docsa, T.; Tóth, B.; Gergely, P. J. Med. Chem. 2001, 44, 2843. (c) Thenmozhiyal, J. C.; Wong, P. T. H.; Chui, W. K. J. Med. Chem. 2004, 47, 1527. (d) Muccioli, G. G.; Fazio, N.; Scriba, G. K. E.; Oppitz, W.; Cannata, F.; Poupaert, J. H.; Wouters, J.; Lambert, D. M. J. Med. Chem. 2006, 49, 417. (e) Kaschani, F.; Clerc, J.; Krahn, D.; Bier, D.; Hong, T. N.; Ottmann, C.; Niessen, S.; Colby, T.; van der Hoorn, R. A. L.; Kaiser, M. Angew. Chem., Int. Ed. 2012, 51, 5230. (f) Nakajima, M.; Itoi, K.; Takamatsu, Y.; Kinoshita, T.; Okazaki, T.; Kawakubo, K.; Shindo, M.; Honma, T.; Tohjigamori, M.; Haneishi, T. Antibiotics 1991, 44, 293.

11. (a) Fujiwara, Y.; Fu, G. C. J. Am. Chem. Soc. 2011, 133, 12293. (b) Fraile, J. M.; Lafuente, G.; Mayoral, J. A.; Pallarés, A. Tetrahedron 2011, 67, 8639. (c) Wehner, V.; Blum, H.; Kurz, M.; Stilz, H. U. Synthesis 2002, 2023. (d) Pesquet, A.; Daïch, A.; Hijfte, L. V. J. Org. Chem. 2006, 71, 5303.

12. (a) Lovely, C. J.; Du, H.; He, Y.; Dias, H. V. R. Org. Lett. 2004, 6, 735. (b) Alsina, J.; Scott, W. L.; O’Donnell, M. J. Tetrahedron Lett. 2005, 46, 3131. (c) Lu, Y.; Geib, S. J.; Damodaran, K.; Sui, B.; Zhang, Z.; Curran, D. P.; Zhang, W. Chem. Commun. 2010, 46, 7578. (d) Albers, H. M. H. G.; Hendrickx, L. J. D.; van Tol, R. J. P.; Hausmann, J.; Perrakis, A.; Ovaa, H. J. Med. Chem. 2011, 54, 4619. (e) Dhara, K.; Midya, G. C.; Dash, J. J. Org. Chem. 2012, 77, 8071. (f) Charton, J.; Delarue, S.; Vendeville, S.; Debreu-Fontaine, M. -A.; Girault-Mizzi, S.; Sergheraert, C. Tetrahedron Lett. 2001, 42, 7559. (g) Ambrozak, A.; Gütschow, M. J. Heterocyclic Chem. 2006, 43, 807. (g) Brockmeyer, F.; Kröger, D.; Stalling, T.; Ullrich, P.; Martens, J. Helv. Chim. Acta 2012, 95, 1857.

13. (a) Dyatkin, A. B. Tetrahedron Lett. 1997, 38, 2065. (b) Bujisman, R. C.; Vuuren, E. V.; Sterrenburg, J. G. Org. Lett. 2001, 3 , 3785. (c) Dieltiens, N.; Claeyes, D. D.; Zhdankin, V. V.; Nemykin, V. N.; Allaert, B.; Verpoort, F.; Stevens, C. V. Eur. J. Org.

Chem. 2006, 2649.

14. (a) Nicolaou, K. C. Tetrahedron 1981, 37, 4097. (b) Tiecco, M.; Tingoli, M.; Testaferi, L. Pure App. Chem. 1993, 65, 722. (c) Knight, D. W. Progress in Heterocyclic Chemistry 2002, 14, 19. (d) Fugita, K. Rev. Heteroatom Chem. 1997, 16, 101. (e) Petragnani, N.; Stefani, H. A.; Valduga, C. J. Tetrahedron 2001, 57, 1411. (f) Khokhar, S. S.; Wirth, T. Eur. J. Org. Chem. 2004, 4567. (g) Aprile, C.; Gruttadauria, M.; Lo Meo, P.; Riela, S.; Nato, R. Heterocycles 2002, 57, 293. (h) Tiecco, M.; Testaferi, L.; Santi, C. Eur. J. Org. Chem. 1999, 797.

15. (a) Bucherer, H. T.; Brandt, W. J. J. Prakt. Chem. 1934, 5, 129. (b) Edward, J. T.; Jitrangsri, C. Can. J. Chem. $1975,53,3339$. 16. (a) Mojsilović, B. M.; Bugarčić, Z. M. Heteroatom Chem. 2004, 15, 468. (b) Bugarčić, Z. M.; Mojsilović, B. M.; Divac, V. M. J. Mol. Cat A: Chem. 2007, 272, 288. (c) Šmit, B.; Bugarčić, Z. J. Heterocyclic Chem. 2010, 47, 1443.

17. (a) Toshimitsu, A.; Terao, K.; Uemura, S. J. Org. Chem. 1986, 51, 1724. (b) Terao, K.; Toshimitsu, A.; Uemura, S. J. Chem. Soc. Perkin Trans. 1 1986, 1837.

18. (a) Jones, T. H.; Blum, M. S. J. Org. Chem. 1980, 45, 4778. (b) Occhiato, E. G.; Brandi, C.; Ferrari, A.; Guarna, A. J. Org. Chem. 2005, 70, 4542. (c) Tiecco, M.; Testaferi, L.; Bagnoli, L.; Scarponi, C. Tetrahedron: Asymmetry 2008, $19,2411$. 